\title{
Correction to: Steep medial tibial slope and prolonged delay to surgery are associated with bilateral medial meniscus posterior root tear
}

Takaaki Hiranaka $^{1,2} \cdot$ Takayuki Furumatsu $^{1}$ (D) $\cdot$ Yuki Okazaki $^{1} \cdot$ Tadashi Yamawaki $^{3} \cdot$ Yoshiki Okazaki $^{1} \cdot$ Yuya Kodama $^{1}$. Yusuke Kamatsuki ${ }^{1}$ - Toshifumi Ozaki ${ }^{1,2}$

Published online: 2 January 2021

(c) European Society of Sports Traumatology, Knee Surgery, Arthroscopy (ESSKA) 2020

\section{Correction to: \\ Knee Surgery, Sports Traumatology, Arthroscopy \\ https://doi.org/10.1007/s00167-020-06079-1}

Authors would like to update the changes in affiliation. Corrected version of affiliation updated here.

The original article has been corrected.

Publisher's Note Springer Nature remains neutral with regard to jurisdictional claims in published maps and institutional affiliations.

The original article can be found online at https://doi.org/10.1007/ s00167-020-06079-1.

Takayuki Furumatsu

matino@md.okayama-u.ac.jp

1 Department of Orthopaedic Surgery, Okayama University Hospital, 2-5-1 Shikatacho, Kitaku, Okayama 700-8558, Japan

2 Department of Orthopaedic Surgery, Okayama University Graduate School of Medicine, Dentistry, and Pharmaceutical Sciences, 2-5-1 Shikatacho, Kitaku, Okayama 700-8558, Japan

3 Department of Orthopaedic Surgery, Kousei Hospital, 3-8-35 Kouseicho, Kitaku, Okayama 700-0985, Japan 